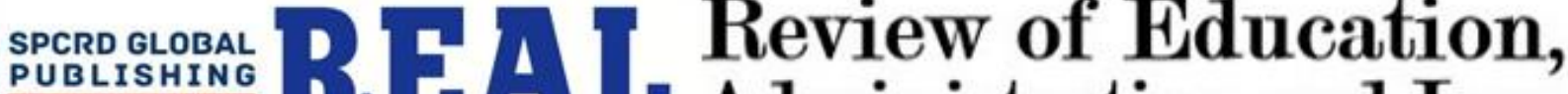

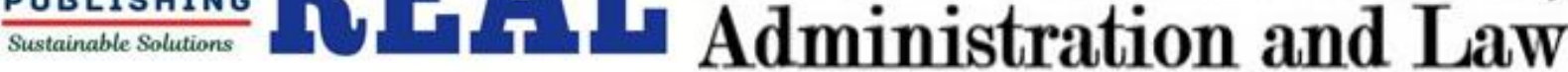 Journal homepage: http://real.spcrd.org ISSN (Print): 2708-1788
}

\section{Quantity of Feedback Provision: University Students' Perceptions from Gender Perspectives and Association with Achievement}

\author{
a Bashir Hussain, ${ }^{b}$ Asma Riaz, ${ }^{c}$ Uzma Shahzadi \\ a PhD Assistant Professor, Department of Education, Bahauddin Zakariya University, Multan, Pakistan: \\ bashirhussain@bzu.edu.pk \\ ${ }^{\mathrm{b}}$ M. Phil Scholar, Department of Education, Bahauddin Zakariya University, Multan, Pakistan: asma.riazoo12@gmail.com \\ c Assistant Professor, Department of Education, University of Sargodha, Sargodha, Pakistan: uzmashah_bzu@yahoo.com
}

Corresponding author’s email address: bashirhussain@bzu.edu.pk

\begin{tabular}{l}
\hline ARTICLE DETAILS \\
\hline History: \\
Accepted 25 February 2019 \\
Available online 3o June 2019 \\
\hline
\end{tabular}

Keywords:

Feedback Quantity, Gender; Achievement; University

\section{JEL Classification:}

L49, L42, J16,

DOI: $10.47067 /$ real.v2i1.6

\begin{abstract}
Current Feedback plays a highly significant role in enhancing students' learning. Feedback provision helps students grow and learn from their mistakes. Feedback also informs students about their strengths, weaknesses, and helps them in determining their level of success. It is, therefore, important to supply students enough information, useful for them to future their learning. In this context, the quantity of feedback provision is also important in addition to the quality of feedback as provides base. The researchers observed that this basic component of quantity of feedback provision is also in question in universities of Pakistan before moving to the most useful component of quality of feedback. This research was, therefore, conducted to examine the quantity of feedback practices in three universities of Multan city. The study further examines quantity of feedback provisions to students from the perspective of their gender and its association with their achievement. The study was descriptive in nature, so a questionnaire based on five-point Likert scale was used to collect data from the students. The population of the study included students from three selected universities of Multan city i.e., the largest one Bahauddin Zakariya University, and medium size Women University and Multan campus of the University of Education, Lahore. Population included of all students from three selected universities of Multan and a sample of 871 students was selected using the multistage cluster sampling method. Data were analyzed by using mean and standard deviation from descriptive statistics, along with independent sample t-test and correlation from inferential statistics. The key findings showed that the quantity of feedback provisions to students is not enough. It was also found that female students perceive that they get more quantity of feedback as compared to male students. Furthermore, results also revealed that quantity of feedback provisions and quantity of feedback provisions to students are positively associated with each other.
\end{abstract}




\section{Introduction}

The impact An extensive and huge amount of research exists related to provision of feedback to students and its importance for students' learning and growth in higher education. Many authors have provided various descriptions of feedback. For example, Baliram and Ellis (2019) stated that feedback refers to the answer to students' thoughts, that are likely to be presented by them in their written work or it refers to discussion about any topic that is being taught by teachers in classroom. DeNisi and Kluger (2000) classified feedback as information provided to someone who is involved in any task by someone who is supposed to observe or evaluate, about how the task was performed.

Most recently, feedback has been explained as an information by which students can confirm, rectify or reorganize their process of learning, reform inter-disciplinary knowledge, or they might adjust their self-perceptions, tasks and cognitive strategies (Conrad, 2013; King, 2016). Likewise, Singh (2019) also described feedback as a piece of information, which is likely to increase students' understanding of the task and their ability to perform a next task given to them. Hattie and Gan (2011) argued that feedback can possibly serve many functions, but it depends on how it is perceived by the students. Feedback can have both positive and negative impact on students if it is not provided correctly.

The literature proves that feedback has several benefits for students' learning. For example, Hyland (2000) elaborated that in all learning situations, feedback is an important element as it provides many benefits to students, including increase in student achievement, improvement in students' comprehension and competences, and boost students' confidence and motivation. But for feedback to be more effective and efficient, it must be productive, thought provoking, individualized, timely and related to assessment standards (Singh, 2019). Feedback is also a part of formative assessment as, Sadler (1998) described that formative assessment especially designed to provide feedback on students' performance with a purpose to enhance learning. Ecclestone and Pryor (2003) argued that an effective formative assessment feedback provides opportunities for students to comprehend their own knowledge in a way to realize on how to become better.

Furthermore, many authors have highlighted the importance of feedback considering various factors related to it. For example, Gibbs and Simpson (2004) emphasized the significance of feedback as long as it is clear, logical, timely and applied by students on their future learning. Yorke (2003) also stressed that content of the feedback, student's knowledge, and psychology of teachers are extremely important in receiving and giving feedback for students' learning. It is thus clear that appropriate weightage be given to these factors while providing feedback to students.

Although feedback is very crucial for students' learning and growth, it has been observed that the grade or scores are the most widely used types of feedback, provided to students on their written tasks or performance (Marzano, 2000; Oosterhof, 2001). Grades are numeric scores that provide brief explanation to all concerned people about students' achievement (Smith \& Gorard, 2005). In this connection, Ypsilandis (2002) suggested that the provision of suitable amount of feedback to students in accordance with their level (i.e. educational background), along with explanation of material, might be ideal for students' learning. The suitable amount of feedback also refers to the quantity of feedback.

The quantity of feedback must be planned while proving feedback. Too much feedback might devastate students and may limit their capability to process the information, particularly when the 
feedback is negative. It is best to plan several sessions of feedback if quantity of material to be debated is comprehensive. This method provides students an opportunity to consider the given feedback for improvement and look for further information and direction at subsequent sessions (Schartel, 2012). Problem of feedback quantity has been highlighted by students in many studies. Students do not like single-line feedback and perceive it negatively if it does not give enough information to be useful (Ferguson, 2011; Higgins, Hartley \& Skelton 2002). Student's ability to use the feedback requires students' engagement (Price, Handley, Millar \& O'donovan, 2010) with the feedback and students prefer more informative feedback that can be used by them in future for learning of similar concepts (Brown \& Glover, 2006; Carless, 2006; Ferguson, 2011).

Though many learners would want a plenty of feedback (Hyland, 2000), the size or length of the feedback does not necessarily influence students' learning. Even though longer feedback comments might have a positive impact on revisions if used by students (Treglia, 2009). But on the other hand, quantity of feedback might be problematic as less important but frequent comments may overshadow the most important comments (Vardi, 2012). Ambrose, Bridges, DiPietro, Lovett and Norman (2010) also argued that too much feedback can be challenging for students and can have a negative influence on students' learning. Lilly, Richter and Rivera -Macias (2010) also found that students didn't feel that the amount or length of feedback was essential to enhance their learning. They further found that students believed that excessive feedback was no better than too short comments and thus feedback must be brief and concise.

Molloy and Boud (2012) further discussed that the quantity or amount of feedback does not always be linked to the usefulness and the meaningfulness of feedback comments to learning. There may be, however, conditions when large amount of feedback have impact on students' learning, but this depends on students' experiences and whether they find feedback comments useful for their learning or not. For example, relationship between the learner and teacher, so that the teacher develop a close insight into students' work over time, this might be more vital to students' learning than the volume of feedback in any program. Molloy and Boud (2012) further argued that in addition to increasing the frequency of feedback, it is also essential that feedback comments on the students' work be provided clearly and collaboratively to improve their performance is obvious.

Most learners acknowledge the value of feedback (Higgins et al., 2002; Hyland, 2000) from their teachers. Hyland (2005) stated that 90\% of students consider that feedback comments from teachers may help them find their strengths and weaknesses and to improve their future performance. Students believe that feedback can stimulate the sense of achievement in them. Further research showed that not every student tries to seek feedback with the same effort. For example, Sinclair and Cleland (2007) found that female learners try to get more feedback than male learners and high achievers try to get more feedback than low achievers. Bevan, Badge, Cann, Willmott, and Scott (2008) found that overall students were positive about the amount of feedback they received from teachers and, therefore, also connected feedback with their earning in a positive manner. But it was seen that students were not much satisfied with the actual quantity and amount of feedback comments, or its value.

Considering the literature, the quantity of feedback provision is also important in addition to the quality of feedback as provides base. The researchers observed that this basic component of quantity of feedback provision is also in question in universities of Pakistan before moving to the most useful component of quality of feedback. There is a shortage of research studies regarding the quantity of feedback provisions although many aspects of teachers' feedback have been covered i.e., perceptions of teachers, timeliness of feedback, feedback gaps, types of feedback. Similarly, although areas of assessment 
and evaluation have been given much importance in Pakistan, but little consideration is given to the quantitative aspect of feedback as a part of the formative assessment. This research was, therefore, conducted to examine the quantity of feedback provisions in three selected universities of Multan. Moreover, this study examines quantity of feedback provisions to students from the perspective of their gender and its association with their achievement.

\section{Objectives and Hypotheses}

This research study mainly examines the students' perceptions about the quantity of feedback provisions by the teachers. The main objectives of the research study were following:

- $\quad$ To examine the quantity of feedback provisions to students by their teachers in three selected universities of Multan as perceived by students.

- To examine the quantity of feedback provisions to students in selected universities of Multan from perspective of their gender and its association with their achievement.

Keeping in view the study objectives, two sets of research and null hypotheses were stated to examine the perceptions of students about quantity of feedback provisions from perspective their gender and achievement.

- Research Hypotheses 1 (H1): A statistically significant gender differences exists in university students' perceptions about the quantity of feedback provisions.

- Null Hypotheses 1 (Ho): A statistically insignificant gender differences exists in university students' perceptions about the quantity of feedback provisions.

- $\quad$ Research Hypotheses 2 (H1): A statistically significant association exists between the university students' achievement and their perceptions about the quantity of feedback provisions.

- Null Hypotheses 2 (Ho): A statistically insignificant association exists between the university students' achievement and their perceptions about the quantity of feedback provisions.

\section{Research Methodology}

\subsection{Research Design, Population and Sample}

Being descriptive in the nature, this quantitative study used questionnaire as a tool, following the survey research design. All students from three selected universities of Multan city served as a population. These universities include one large-size Bahauddin Zakariya University and two medium/small size universities of Multan i.e., Multan campus of University of Education Lahore, and the Women University, Multan. Using the multistage cluster sampling method, a total sample of 871 students was selected from three universities. Of the eight faculties of the Bahauddin Zakariya University, first three faculties were randomly selected. From these three faculties, 19 departments were randomly selected out of a total of 59 departments. One class was selected from each department, all individual students were selected as sample, subject to their consent for taking part in the study. The same procedure was adopted for the selection of participants from other universities. Of five faculties of Women University, three faculties were selected. In these three faculties, there were 24 departments. Of these 24 departments, nine departments were randomly selected as a sample and one class was selected as a sample from each selected department. Finally, all students from these selected classes were invited to participate in the study. Similarly, first three faculties were selected as sample from a total of four faculties from University of Education. Of 12 departments of three selected faculties, one department was selected randomly as a sample. From each selected department, one class was selected as sample, and all students were taken as sample from selected classes. Finally, a total of 871 students were selected as sample from three universities. 


\subsection{Research Tool, Data Collection, and Analysis}

For the collection of data, a two-section questionnaire was designed based on large review of the literature. The first section comprised demographic data and second one comprised six set of items related to the quantity of feedback provisions. Each set comprised further items and was based on fivepoint Likert scale. The Cronbach's Alpha value of the tool, comprising all items, was calculated and was o.81. The items on the questionnaire were validated through the literature and experts' opinions at Bahauddin Zakariya University Multan. The data were collected through questionnaires from the students. Nine hundred (900) questionnaires were distributed among students by the researchers and 871 were returned by them. Thus, response rate of the questionnaire was $97 \%$.

For the analysis of data, all items of the six set of items were first entered into MS-Excel and the average summed scores were calculated. These six summed scores were then considered as separate six items and then data were shifted to SPSS. Finally, mean values and standard deviation values were calculated from descriptive statistics for the six set of items. MS-Excel was used to calculate the mean and standard deviation of the six set of statements about the quantity of feedback provisions to students. Furthermore, using SPSS, independent t-test was used to calculate difference between the perceptions of male and female students regarding the quantity of feedback provisions from inferential statistics. Pearson correlation was also used to examine association between students' achievement and their perceptions about the quantity of feedback provisions.

\section{Results}

Results have been presented in three parts, in response to three objectives and their research and null hypotheses.

\subsection{Students' perceptions about the Quantity of Feedback Provisions}

This section provides the analysis of data about perceptions of university students regarding the quantity of feedback provisions. To examine quantity of feedback provisions, mean and standard deviation of six set of items were calculated and, as shown in Table 1.

Table 1: Students' perceptions about the provision of feedback in terms of quantity

\begin{tabular}{|c|c|c|c|}
\hline No. & Statements & Mean & S.D \\
\hline $\mathbf{1}$ & Receive feedback frequently on work & 3.28 & 1.09 \\
\hline $\mathbf{2}$ & $\begin{array}{c}\text { Receive feedback every time on } \\
\text { taskignments. }\end{array}$ & 2.93 & 1.19 \\
\hline $\mathbf{3}$ & $\begin{array}{c}\text { Teachers always guide regarding } \\
\text { mistakes. }\end{array}$ & 3.13 & 1.28 \\
\hline $\mathbf{4}$ & $\begin{array}{c}\text { Frequency of feedback towards more } \\
\text { learning. }\end{array}$ & 4.17 & 1.07 \\
\hline $\mathbf{5}$ & $\begin{array}{c}\text { Teachers provide adequate amount of } \\
\text { feedback. } \\
\text { Sufficient details to make feedback } \\
\text { effective. }\end{array}$ & 3.48 & 1.12 \\
\hline
\end{tabular}

Table 1 indicates that mean values of the first set of items is 3.28 , which indicates a very low level 
of agreement against items that the students receive feedback frequently on their work tasks. Second set of items has a mean value of 2.93, which shows that students disagreed that they receive feedback every time on their assignments. The mean value for third set of items is 3.13, which shows that students slightly agreed that their teacher always guide regarding their mistakes. Fourth set of items has mean value of 4.17 , which shows that students agreed with the statement that frequency of feedback helps them towards their learning. The mean value of the fifth set of items is 3.48 , which shows that the students slightly agreed that their teachers provide adequate amount of feedback to them. Mean value of the last set of items is 3.66, which shows that students agreed at moderate level that their teachers provide sufficient details to them to make feedback effective. Overall mean (i.e. $M=3.44$ ) showed that students do not get sufficient amount of feedback on their work. It is evident from the results that most students perceive that the quantity of feedback provisions to them, by their teachers, in three selected universities of multan city is low. However, the average value of standard deviation is 1.16 , which shows that there is moderate level of consensus of students about quantitative provision of feedback to them by their teachers.

\subsection{Difference between students' perceptions about quantity of feedback provisions by gender}

Table 2 presents the results about gender differences between students' perceptions about the quantity of feedback provisions to students by their teachers, using independent sample t-test for the analysis of data.

Table 2: Gender differences between students' perceptions about quantity of feedback provisions

\begin{tabular}{|r|l|l|l|l|l|l|}
\hline Feedback & Gender & N & Mean & t & df & $\begin{array}{c}\text { Sig. } \\
\text { (2-tailed) }\end{array}$ \\
\hline \multirow{2}{*}{ Quantity } & Male & 330 & 20.13 & - & 869 & 0.001 \\
\cline { 2 - 5 } & Female & 541 & 20.97 & 3.29 & 869 & 0.001 \\
\hline
\end{tabular}

Table 4 indicates the difference between the mean values of male $(M=20.13)$ and female $(M=$ 20.97) students regarding the quantity of feedback provisions to them by their teachers. The significance value is 0.001 . This value is less than 0.05 , which indicates that the difference between the perceptions of male and female is statistically significant. This difference further specifies that female students perceive that they are provided with more quantity of feedback on their work than their male classmates.

\subsection{Association between students' perceptions about the quantity of feedback provisions and their achievement}

Table 4.3 presents association between students' perceptions about the quantity of feedback provisions and their achievement, using Pearson correlation and inferential statistics. 


\begin{tabular}{|l|l|c|c|}
\hline \multirow{2}{*}{ Feedback/Achievement } & Association & Achievement & $\begin{array}{c}\text { Quantity } \\
\text { of Feedback }\end{array}$ \\
\hline \multirow{2}{*}{ Achievement } & $\begin{array}{c}\text { Pearson } \\
\text { Correlation }\end{array}$ & 1 & 0.07 \\
\cline { 2 - 4 } & \multicolumn{1}{|c|}{ Sig. (2- } & & 0.048 \\
\hline
\end{tabular}

Table 3: Association between quantity of feedback provisions and students' achievement

*. Correlation is significant at the level o.05 (2-tailed).

Table 3 clearly indicates that the value of Pearson correlation between students' perceptions about the quantity of feedback provisions to them and their achievement is 0.07, which shows very low positive association. The significance value is 0.048 (i.e., less than 0.05). It shows that university students' perceptions about quantity of feedback provisions to them by their teachers is statistically significantly associated with their academic achievement in a positive way, but to a very low level.

\section{Discussion}

This study found that students perceive that they do not get sufficient quantity of feedback on their work from their teachers in three universities of Multan. Students perceive that quantity of feedback provisions to them is very low. Molloy and Boud (2012) believe that the quantity or amount of feedback does not always be linked with students' learning. Ypsilandis (2002), however, suggested that provision of suitable amount of feedback to students in accordance with their level (i.e. educational background) might be ideal for students' learning. It is, thus, very alarming for teachers, administrators, and policymakers in three university of Multan city that the quantity of feedback provisions to students by teachers is very low and it is thus raising questions on teaching and learning process. This study also found that female students perceive that they are provided with more quantity of feedback on their work than their male classmates. This is probably because, as found by Sinclair and Cleland (2007) in their study, female learners try to get more feedback than male learners and the high achievers try to get more feedback than low achievers. This study also found that university students' perceptions about quantity of feedback provisions to them by their teachers is statistically significantly associated with their academic achievement, but to a very low level. Ypsilandis (2002) also stated that provision of suitable amount of feedback to students in accordance with their level might be ideal for students' learning. In this context, it is important to increase the quantity of feedback to enhance students' achievement at university level.

\section{Conclusions and Recommendations}

Some useful conclusions can be drawn from this research study, and some recommendations accordingly. First, this research concluded that students perceive that the quantity of feedback provisions to them is very low in universities of Multan city. It is, therefore, recommended that teachers need to plan their teaching activities in such way that feedback may be provided to students in a convenient way. Second, this study also found that female students perceive that they are provided with more quantity of feedback on their work than their male fellows. It is highly important to engage male students with learning activities. Finally, this study also found that university students' perceptions about quantity of 
feedback provisions to them by their teachers is statistically significantly associated with their academic achievement, but to a very low level. In this context, it is important to increase quantity of feedback to enhance students' achievement at university level. University teachers, in collaboration with students, policymakers, administrators, may develop some guidelines for promoting more convenient and effective ways of providing feedback to students. This may be very useful for enhancing students' learning experiences.

\section{References}

Ambrose, S. A., Bridges, M. W., DiPietro, M., Lovett, M. C., \& Norman, M. K. (2010). How learning works: Seven research-based principles for smart teaching. John Wiley \& Sons.

Baliram, N., \& Ellis, A. K. (2019). The impact of metacognitive practice and teacher feedback on academic achievement in mathematics. School Science and Mathematics, 119(2), 94-104.

Bevan, R., Badge, J., Cann, A., Willmott, C., \& Scott, J. (2008). Seeing eye-to-eye? Staff and student views on feedback. Bioscience Education, 12(1), 1-15.

Brown, E., \& Glover, C. (2006). Evaluating written feedback. In Innovative assessment in higher education (pp. 101-111). Routledge.

Carless, D. (2006). Differing perceptions in the feedback process. Studies in higher education, 31(2), 219233.

Conrad, D. (2013). Pondering change and the relationship of prior learning assessment to MOOCs and knowledge in higher education. PLA Inside Out: An International Journal on Theory, Research and Practice in Prior Learning Assessment, 2(1).

DeNisi, A. S., \& Kluger, A. N. (2000). Feedback effectiveness: Can 360-degree appraisals be improved? Academy of Management Perspectives, 14(1), 129-139.

Ecclestone, K., \& Pryor, J. (2003). 'Learning careers' or 'assessment careers'? The impact of assessment systems on learning. British Educational Research Journal, 29(4), 471-488.

Ferguson, P. (2011). Student perceptions of quality feedback in teacher education. Assessment \& Evaluation in Higher Education, 36(1), 51-62.

Gibbs, G., \& Simpson, C. (2004). Does your assessment support your students' learning. Journal of Teaching and learning in Higher Education, 1(1), 1-30.

Hattie, J., \& Gan, M. (2011). Instruction based on feedback. In Handbook of research on learning and instruction (pp. 263-285). Routledge.

Hattie, J., \& Gan, M. (2011). Instruction based on feedback. In Handbook of research on learning and instruction (pp. 263-285). Routledge.

Higgins, R., Hartley, P., \& Skelton, A. (2002). The conscientious consumer: Reconsidering the role of assessment feedback in student learning. Studies in higher education, 27(1), 53-64.

Hyland, F. (2000). ESL writers and feedback: Giving more autonomy to students. Language teaching research, 4(1), 33-54.

Hyland, K. (2005). Stance and engagement: A model of interaction in academic discourse. Discourse studies, 7(2), 173-192.

Hyland, K. (2006). Disciplinary differences: Language variation in academic discourses. Academic discourse across disciplines, 17-45.

King, P. E. (2016). When do students benefit from performance feedback? A test of feedback intervention theory in speaking improvement. Communication Quarterly, 64(1), 1-15.

Lilly, J., Richter, U. M., \& Rivera-Macias, B. (2010). Using Feedback to Promote Learning: Student and Tutor Perspectives. Practitioner Research in Higher Education, 4(1), 30-40.

Marzano, R. J. (2000). Transforming Classroom Grading. Association for Supervision and Curriculum Development, Alexandria, VA. 
Molloy, E., \& Boud, D. (2012). Changing conceptions of feedback. In Feedback in higher and professional education (pp. 21-43). Routledge.

Oosterhof, A. (2001). Classroom applications of educational measurement. Prentice-Hall, Inc., Upper Saddle River, New Jersey.

Price, M., Handley, K., Millar, J., \& O'donovan, B. (2010). Feedback: all that effort, but what is the effect? Assessment \& Evaluation in Higher Education, 35(3), 277-289.

Sadler, D. R. (1998). Formative assessment: Revisiting the territory. Assessment in education: principles, policy \& practice, $5(1), 77-84$.

Schartel, S. A. (2012). Giving feedback-An integral part of education. Best practice \& research Clinical anesthesiology, 26(1), 77-87.

Sinclair, H. K., \& Cleland, J. A. (2007). Undergraduate medical students: who seeks formative feedback? Medical education, 41(6), 580-582.

Singh, K. (2019). Lecturer's Feedback and Its Impact on Student Learning: A Study of a Public University in Sarawak, Malaysia. Asian Journal of University Education, 15(3), 83-91.

Smith, E., \& Gorard, S. (2005). 'They don't give us our marks': the role of formative feedback in student progress. Assessment in Education: Principles, Policy \& Practice, 12(1), 21-38.

Treglia, M. O. (2009). Teacher-written commentary in college writing composition: How does it impact student revisions? Composition Studies, 37(1), 67-86.

Vardi, I. (2012). The impact of iterative writing and feedback on the characteristics of tertiary students' written texts. Teaching in higher education, 17(2), 167-179.

Yorke, M. (2003). Formative assessment in higher education: Moves towards theory and the enhancement of pedagogic practice. Higher education, 45(4), 477-501.

Ypsilandis, G. S. (2002). Feedback in distance education. Computer Assisted Language Learning, 15(2), $167-181$. 